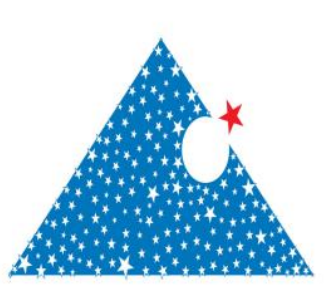

www.dergipark.gov.tr

ISSN:2148-3736

El-Cezerî Fen ve Mühendislik Dergisi

Cilt: 7, No: 2, 2020 (402-409)

El-Cezerî Journal of Science and Engineering

Vol: 7, No: 2, 2020 (402-409)

DOI:10.31202/ecjse.648678

Makale / Research Paper

\title{
Ti6Al4V Alaşımı ve Saf Titanyum (Cp-Ti) Oksidasyon Kinetiği
}

\author{
Aysun AYDAY \\ Sakarya University, Faculty of Engineering, Department of Metallurgical and Materials Engineering, Sakarya, \\ Turkey \\ *ayday@sakarya.edu.tr
}

Received/Geliş: 19.11.2019

Accepted/Kabul: 13.02 .2020

Öz: Ti6Al4V alaşımı ve saf Titanyumun (Cp-Ti) açık atmosferde 600,650 ve $700{ }^{\circ} \mathrm{C}$ için, $1,2,4,8,16,24,48$, 72 saat sürelerinde oksidasyon kinetiği davranışları incelenmiştir. Oksidasyon işlemi sonrası numune yüzeyleri $\mathrm{X}$-ı̧̧ınları difraksiyonu (XRD), taramalı elektron mikroskobu (SEM) yardımı ile incelenmiştir. Termal oksidasyon sonrasında yüzeylerde ince oksit tabakası oluşmuş ve metal içerisine oksijen difüzyonu gerçekleşmiştir. Oluşan oksit tabakası rutil ve anatas formundaki $\mathrm{TiO}_{2}$ 'dir. Yüzeyde oluşan oksit tabakasının kalınlığ 1 , sıcaklık ve süreye bağlı olarak artmaktadır. Oksidasyona uğratılan numunelerin aktivasyon enerjileri hesaplanmıştır. Ti6Al4V için oksidasyon aktivasyon enerjisi $201.3 \mathrm{~kJ} / \mathrm{mol}, \mathrm{Cp}-\mathrm{Ti}$ için ise $269.4 \mathrm{~kJ} / \mathrm{mol}$ hesaplanmıştır.

Anahtar kelimeler: Oksidasyon tabakası, oksidasyon kinetiği, titanyum

\section{Oxidation Kinetics of Ti6Al4V Alloy and Pure Titanium (Cp-Ti)}

\begin{abstract}
The oxidation kinetics behavior of Ti6Al4V alloy and pure $\mathrm{Ti}(\mathrm{Cp}-\mathrm{Ti})$ were investigated under air atmosphere at temperatures of 600,650 and $700{ }^{\circ} \mathrm{C}$ for $1,2,4,8,16,24,48,72 \mathrm{~h}$ have been identified in the study. The oxidized samples were characterized by X-ray diffraction (XRD), scanning electron microscopy (SEM). After thermal oxidation, a thin oxide layer was formed on the surfaces and oxygen diffusion took place into the metal. The oxide layer formed rutile and anatase $\left(\mathrm{TiO}_{2}\right)$ form. The thickness of the oxide layer increased with increasing the oxidation temperature and time The activation energies for oxidation were estimated for Ti6Al4V alloys and Cp-Ti, 201.3kJ/mol for Ti6Al4V and 269.4kJ/mol for Cp-Ti were found, respectively.
\end{abstract}

Keywords: Oxide layers, kinetic study, titanium.

\section{Giriş}

Titanyum ve titanyum alaşımları pozitif mekanik ve fiziksel özellikleri (yüksek mukavemet, düşük yoğunluk, iyi biyouyumluluk, düşük termal iletkenlik vs.) sebebi ile birçok alanda tercih edilen popüler malzeme grubu içerisinde sayılabilir. Diğer taraftan, düşük sertlik, düşük aşınma dayanımı gibi olumsuz yanları nedeni ile de uygulama alanlarını sınırlandırmaktadır [1-6]. Bu olumsuz sebepler ile yüzey özelliklerinin iyileştirilmesi amacı ile kaplama işlemlerine ihtiyaç duyulmaktadır. Farklı ve çok sayıda kaplama işlemleri ile Ti alaşımları yüzeyleri geliştirilmeye çalışılmıştır. Plazma kaplama, anodizasyon, mikro ark oksidasyon, PVD, 1sıl işlemler bu yöntemler arasında sayılabileceklerden bir kaçıdır [2,4,7].

Titanyumun kaplanmasında son yıllarda karşımıza çıkan ve en çok tercih edilen yöntemlerden biri mikro ark oksidasyon yöntemidir. Bu yöntemin amacı öncelikle kullanılan metalik malzemenin metal oksit bileşiği ile yüzeyde karalı ve koruyucu bir tabaka oluşturmaktır. Termal oksidasyon işlemi ise bu yönteme alternatif olarak düşünülmüş ve yüzeyde kararlı bir oksit tabakası üretimi gerçekleştirilmesi hedeflenmiştir. Literatürde de bilindiği üzere, titanyumun oksijene olan afinitesi 
oldukça yüksek olup, oluşan oksit tabaka metal yüzeyinde pasif bir tabakanın oluşumuna neden olmaktadır. Termal oksidasyon işlemi ile oluşan bu oksit tabaka $800{ }^{\circ} \mathrm{C}^{\prime}$ nin üzerinde elde edilmiş ise, pasifizasyon tabaksının daha sert ve kırılgan olduğu bilinmektedir. Titanyum ve alaşımları üzerinde oluşturulan kararlı oksit tabakası yüzeyi koruyucu tabaka olarak görev yapmaktadır Titanyum çeşitli formlarda oksit $\left(\mathrm{TiO}, \mathrm{TiO}_{2}, \mathrm{Ti}_{2} \mathrm{O}_{3}, \mathrm{Ti}_{3} \mathrm{O}_{5}\right)$ oluşturabilir. $\mathrm{Bu}$ oksitlerin tabaka yapıları oldukça komplikedir. En dıştaki oksit tabaka daima oksijenden zengin titanyum dioksittir $[4,8,9]$.

Bu çalışmada yüzey özelliklerini iyileştirmek için termal oksidasyon yöntemi tercih edilmiştir. Amaç yüzeyinde kararlı bir oksit tabakası oluşturmaktır. Yapılan ön çalışmalarda $800^{\circ} \mathrm{C}^{\prime}$ nin üzerinde artan işlem sürelerinde, kırılgan bir oksit tabakası elde edilmiştir. $\mathrm{Bu}$ amaçla, termal oksidasyon (TO) işlemi normal atmosferik koşullarda Protherm laboratuvar tipi firında $600^{\circ} \mathrm{C}, 650$ ${ }^{0} \mathrm{C}$ ve $700^{\circ} \mathrm{C}$ 'ler de 1-2-4-8-16-24-48-72 saat (h) sürelerinde $\mathrm{Cp}$-Ti ve Ti6A14V alaşımı için yapılmıştır. Aşınma ve korozyon direncinde önemli etkisi olan termal oksidasyon işleminin ticari saf titanyum ve alaşımlı titanyumun oksidasyonun kinetik açıdan incelenmesi amaçlanmıştır. Kaplama tabakasının karakterizasyonu SEM mikroskobu, elementel analizi ve X-Işını difraksiyon analiziyle gerçekleştirilmiştir.

\section{Deneysel Çalışmalar}

Bu çalışmada, saf Ti (Cp-Ti) ile Ti6Al4V (wt\%) 6.3\%Al, $4.2 \% \mathrm{~V}, 0.15 \% \mathrm{O}, 0.11 \% \mathrm{Fe}, 0.03 \% \mathrm{C}$, $0.02 \% \mathrm{~N}, 0.001 \% \mathrm{H}$ ve kalan Ti) alaşımları kullanılmıştır. Plaka şeklide kesilen $(2 \times 15 \times 20 \mathrm{~mm})$ numuneler kullanılmıştır. Termal oksidasyon işlemi öncesi yüzeyleri zımparalanan numuneler alkolle temizlenip hava ile kurutulduktan sonra ağırlıkları hassas terazi ile tartılmıştır. Tartım işlemi oksidasyon işlemi sonrasında da tek tek kaydedilmiştir.

Termal oksidasyon parametreleri daha önceki çalışmalarımızdan elde edilen optimum değerler göz önüne alınarak seçilmiştir. Termal oksidasyon işlemi normal atmosferik koşullarda $600{ }^{\circ} \mathrm{C}, 650{ }^{\circ} \mathrm{C}$ ve $700^{\circ} \mathrm{C}^{\prime}$ ler de $1,2,4,8,16,24,48$ ve 72 saat sürelerinde $\mathrm{Cp}$-Ti ve Ti6Al4V alaşımı için yapılmıştır.

İşlem sonrası numunelerin, yüzey morfolojileri Jeol marka (JSM 6060-LU) taramalı elektron mikroskobu (SEM) ile incelenmiştir. Oluşan fazların tespiti için X-ışınları difraksiyonu (XRD) cihazı kullanılmıştır.

Kinetik çalışmaları Eşitlik 1'de verilen Arrhenius denklemine göre ilerlemektedir. [10,11]

$$
\mathrm{k}=\mathrm{A} \cdot \mathrm{e}^{(-\mathrm{Q} / \mathrm{RT})}
$$

burada; k: Oksidasyon Hizı [ $\left.\left(\mathrm{mg} / \mathrm{cm}^{2}\right)^{2} / \mathrm{h}\right]$, Q: Aktivasyon enerjisi (J/mol),T: Sicaklık ( $\left.{ }^{\circ} \mathrm{K}\right) \mathrm{R}: \mathrm{Gaz}$ sabiti $\left(8,3143 \mathrm{cal} / \mathrm{mol}^{\circ} \mathrm{K}\right)$ ve A: Frekans faktörüdür.

$\mathrm{Bu}$ ifadeye göre oksidasyon hızlarının logaritması alınarak oksidasyonun mutlak sıcaklığın tersine bağlı olarak çizilmesi halinde bu grafiğin eğimi $-\mathrm{Q} / \mathrm{R}$ oranını vermektedir. $\mathrm{Bu}$ sebeple; öncelikle Eşitlik 2 yardımı ile çizilen $\left(\Delta \mathrm{W}^{2}-\mathrm{t}\right)$ diyagramlarının eğiminden oksidasyon hızı (k) hesaplanmıştır $[9,10]$.

$$
\Delta \mathrm{W}^{\mathrm{n}} / \mathrm{A}=\mathrm{kt}
$$

$\mathrm{Bu}$ eşitlikte $\Delta \mathrm{W} / \mathrm{A}$ : Numunenin birim yüzey alanında meydana gelen kütle $\operatorname{artış1~}\left(\mathrm{mg} / \mathrm{cm}^{2}\right)$, A:Numune yüzey alanı $\left(\mathrm{cm}^{2}\right), \mathrm{k}$ : Oksidasyon Hızı $\left(\mathrm{mg} / \mathrm{cm}^{2}\right)^{2} / \mathrm{h}, \mathrm{t}$ : Oksidayon işlem süresi (saat-h)'ni ifade etmektedir. 
Oksidasyon davranışı parabolik olduğu için, eşitlik 2'de n değeri 2 alınmaktadır. Her bir numune için $(\Delta \mathrm{W} / \mathrm{A})^{2}$-t eğrileri çizilmiş ve eğimlerinden oksitlendirilen numunelerinin oksidasyon hızı $(\mathrm{k})$ değerleri hesaplanmıştır.

\section{Deney Sonuçlarının Değerlendirilmesi}

Protherm marka sabit 1 sitma/soğutma hızı $\left(10^{\circ} \mathrm{C} / \mathrm{dk}\right)$ olacak şekilde numuneler sırası ile $600^{\circ} \mathrm{C}, 650$ ${ }^{0} \mathrm{C}$ ve $700^{\circ} \mathrm{C}$ 'ler de $1,2,4,8,16,24,48$ ve 72 saat sürelerinde termal oksidasyon işlemine tabi tutulmuştur. Cp-Ti ve Ti6Al4V alaşımı için 1, 8, 48 ve 72 saat süreleri için oksidasyon işlemi görmüş numunelerin SEM görüntüleri Şekil 1'de ve Şekil 2'de sırası ile verilmektedir. Farklı sıcaklıklarda ve çeşitli sürelerde oluşan oksit tabakasının yüzey morfolojisinin incelenmesi birtakım farklılıkları göstermiştir.
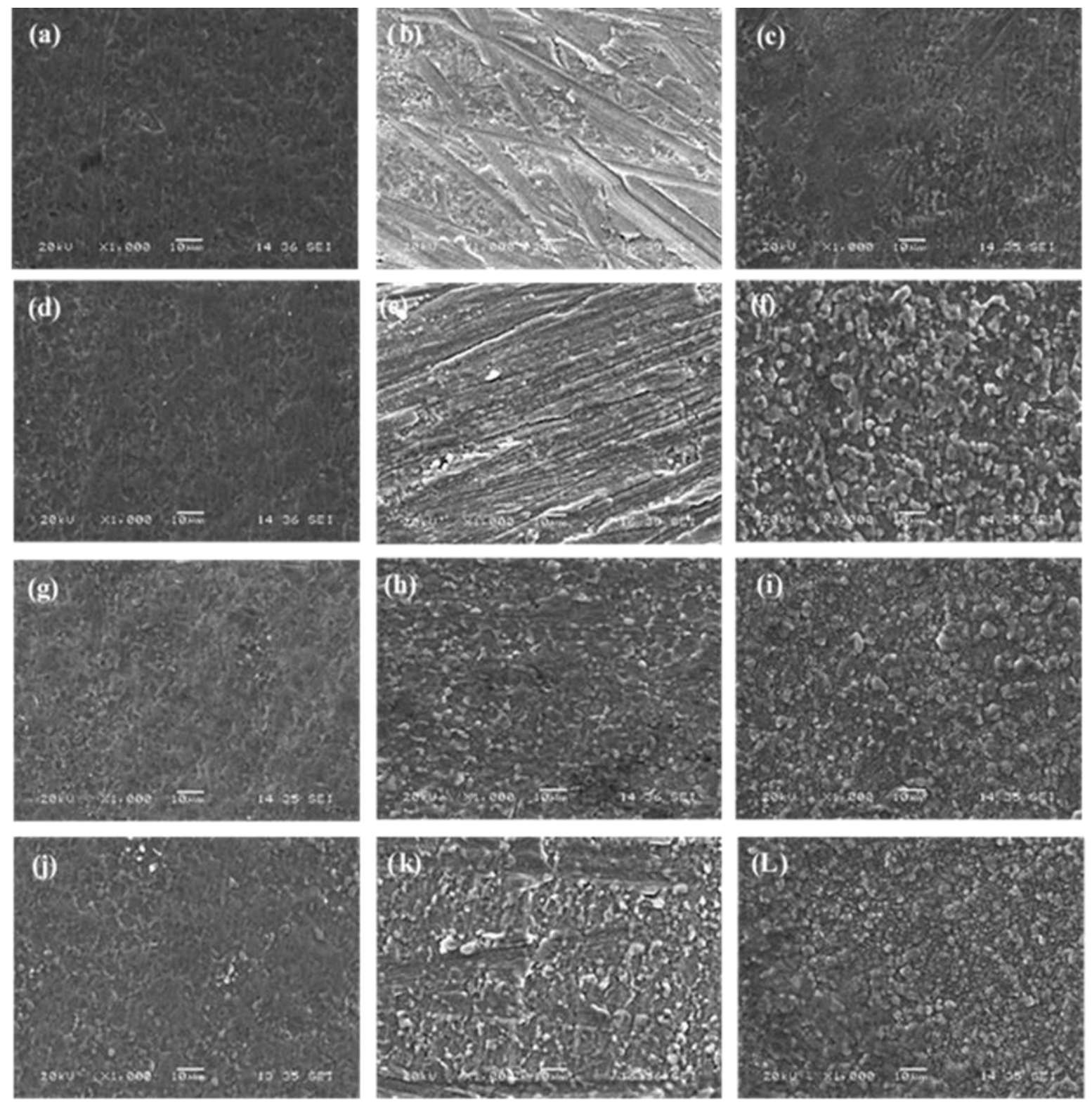

Şekil.1. Termal oksidasyon işlemi sonrası Cp-Ti numunesinin yüzey morfolojisi (a),(d),(g),(j) $600^{\circ} \mathrm{C} ; 1,8,48$ ve $72 \mathrm{~h}$; (b), C),(h),(k)650 ${ }^{\circ} \mathrm{C} ; 1,8,48$ ve $72 \mathrm{~h}$; (c),(f),(i),(L) $700^{\circ} \mathrm{C}$ içim $1,8,48$ ve $72 \mathrm{~h}$

Artan sıcaklık ve süreler de oksit parçacıkları dışa doğru büyümüş ve yüzeyin tümünü kaplamıştır. $600{ }^{\circ} \mathrm{C}$ 'de 1 saatten 8 saate oksidasyon süresindeki artış, alaşımların yüzeyini kaplayan ince bir 
oksidasyon parçacıklarının oluşmasına neden olmuştur. $\mathrm{Bu}$ fark 8 saat oksidasyona uğratılan numunelerde (Şekil 1f ve Şekil 2f), maksimum sıcaklıklarda Cp-Ti ve Ti6Al4V alaşımı için daha belirgin olmuştur. Benzer durum 72 saat süreyle oksidasyon işlemi yapılan numuneler içinde geçerlidir. Maksimum oksidasyon işlem süresi sonunda yüzeyde oluşan oksit tabakası yüzeyde homojen bir dağılım göstermiştir.
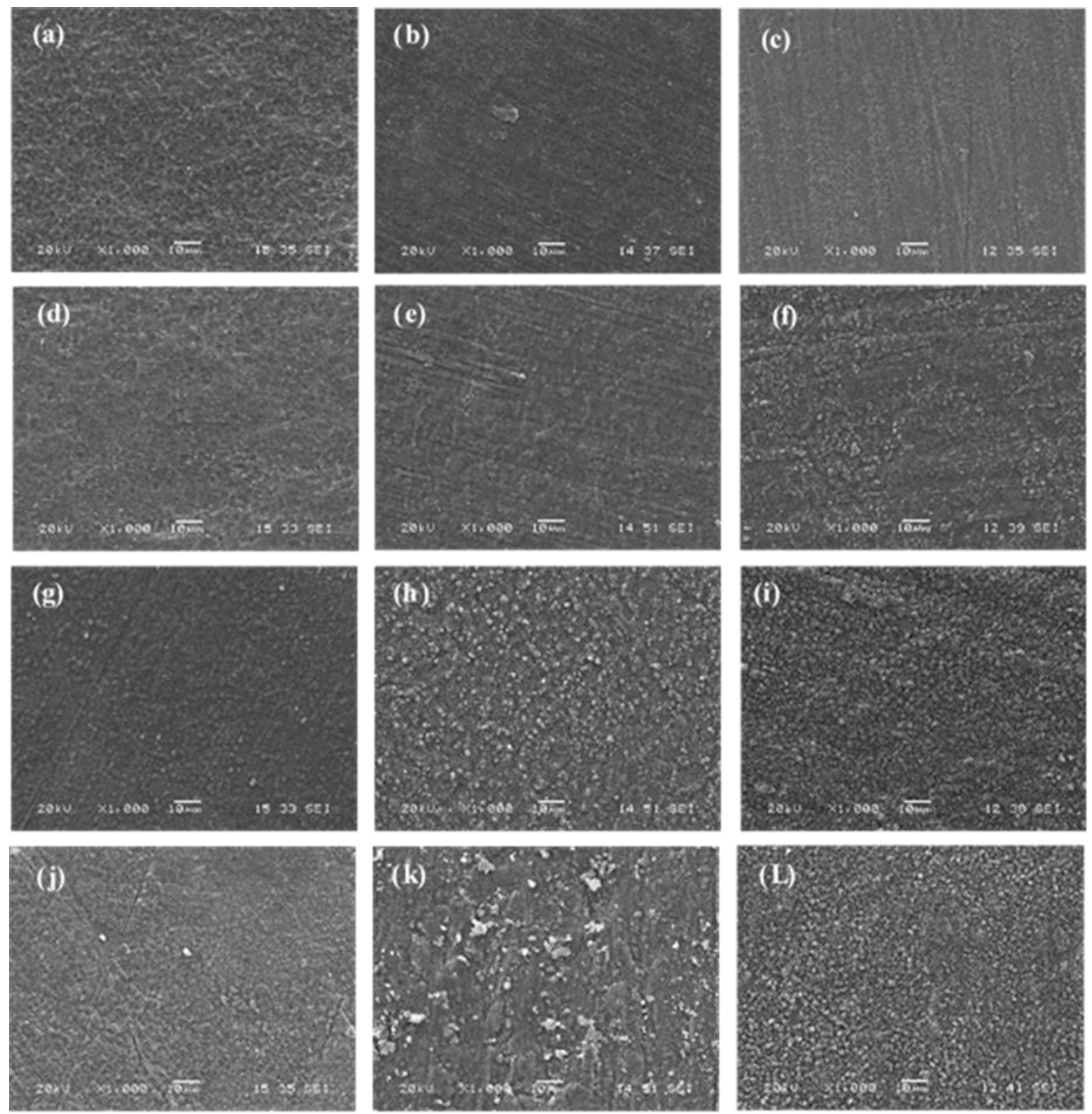

Şekil.2. Termal oksidasyon işlemi sonrası Ti6Al4V numunesinin yüzey morfolojisi (a),(d),(g),(j) $600^{\circ} \mathrm{C} ; 1,8,48$ ve $72 \mathrm{~h} ;(\mathrm{b}),\left(\mathrm{C},(\mathrm{h}),(\mathrm{k}) 650^{\circ} \mathrm{C} ; 1,8,48\right.$ ve $72 \mathrm{~h}$; (c),(f),(i),(L) $700^{\circ} \mathrm{C}$ içim $1,8,48$ ve $72 \mathrm{~h}$

Metalik malzemeler ve alaşımların artan sıcaklık ve süreye bağlı olarak termal oksidasyon davranışları incelendiğinde, genellikle bu malzemelerin sergiledikleri oksidasyon davranışlarının lineer ve parabolik olmak üzere iki evreden oluştuğu görülmektedir [12]. Yapılan çalışmalarda $[10,13,14], 600-700{ }^{\circ} \mathrm{C}$ 'nin üstündeki termal oksidasyon sicakliklarında artan zamanla, oksidasyon hızı hızlı bir şekilde azalma göstermekte yani parabolik davranış göstermektedir. O sebeple farklı yüksek sicaklıklarda oksitlendirilen numunelerin parabolik izotermal oksidasyon sabitleri (k), yukarıda verilen eşitlik 2 ifadesi kullanılarak hesaplanmaktadır. 
Cp-Ti ve Ti6Al4V alaşımının 600,650 ve $700{ }^{\circ} \mathrm{C}$ 'deki izotermal oksidasyon deneyleri neticesinde sonrasında elde edilen ağırlık artışı ve zaman eğrileri şekil 3 (a) ve şekli 3 (b)'de verilmiştir. Alınan eğrilerden de görüldüğ̈̈ üzere zamana ve sıcaklığa bağlı her bir oksidasyon numunesinin ağırlık artışının parabolik olduğu net bir şekilde görülmektedir.
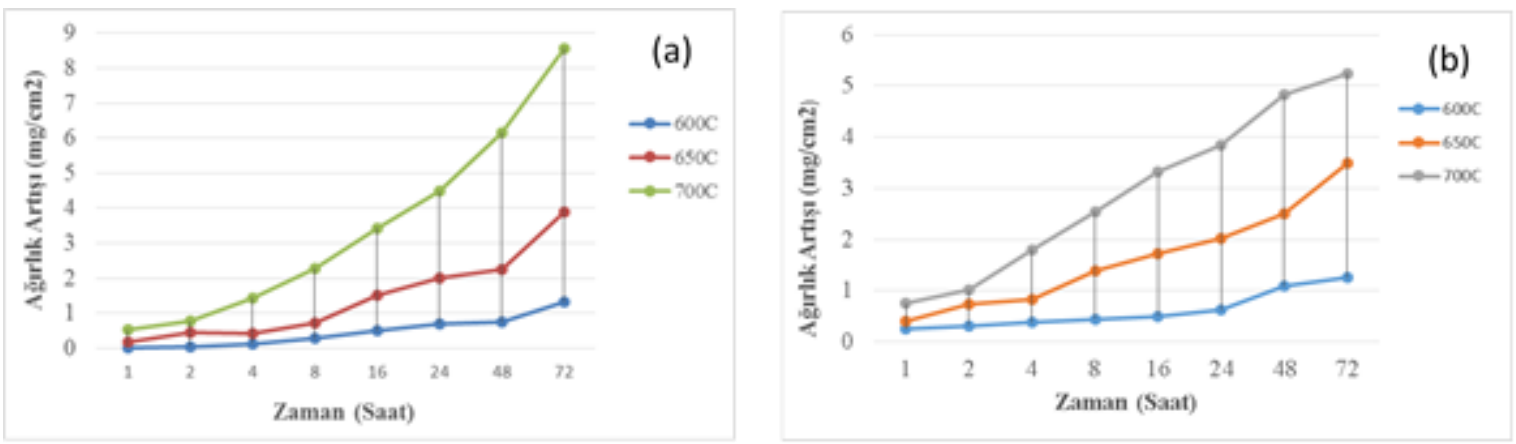

Şekil 3. 600, 650 ve $700{ }^{\circ} \mathrm{C}^{\prime}$ de 72 saat süreyle oksitlendirilen numunelerinin kütle artış eğrileri (a) Cp-Ti, (b) Ti6Al4V

Şekil 3'deki değerlerin karelerinin, süreye bağlı değişimleri Şekil 4 (a) ve (b)'de sırası ile Cp-Ti ve Ti6A14V alaşım numunesi için verilmiştir. Çizilen grafiklerin eğiminden sırası ile her bir sıcaklık için " $k$ " oksidasyon hızı sabitleri belirlenmiştir. Hesaplanan oksidasyon hızı değerleri Tablo 1'de verilmiş̧tir. Hesaplanan oksidasyon sabitleri Arrhenius eşitliği 1'de yerine konularak aktivasyon enerjilerine geçiş yapılmıştır.

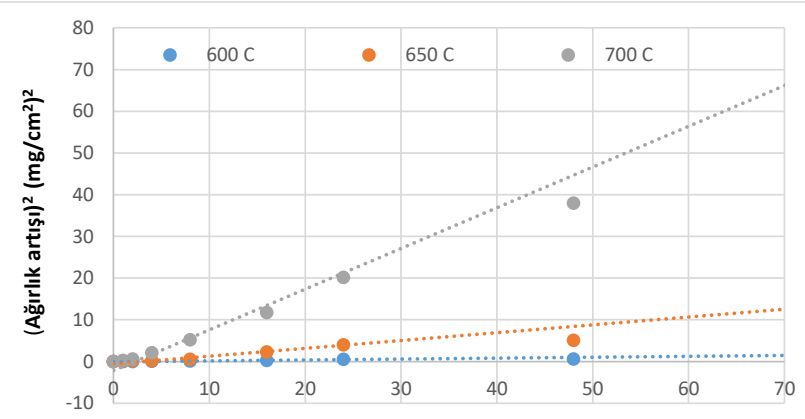

(a)

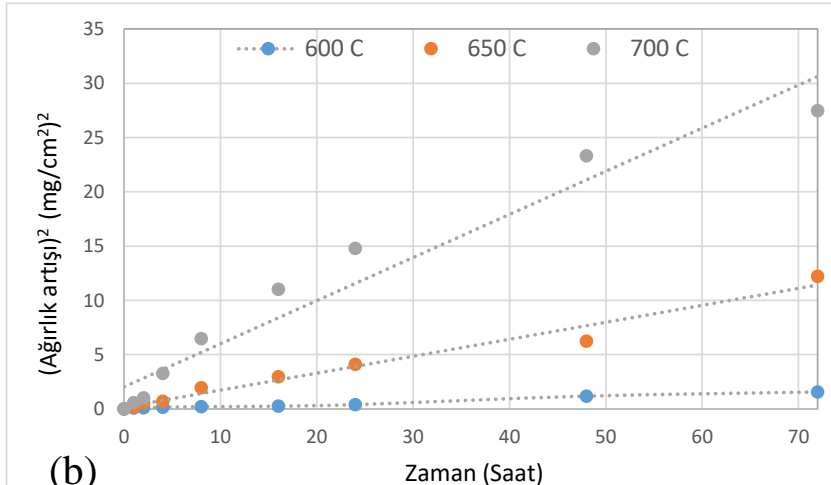

(b)
Zaman (Saat)

Şekil 4. 600, 650 ve $700{ }^{\circ} C^{\prime}$ 'de 72 saat süreyle oksitlendirilen numunelerinin kütle artışlarının kareleri alınarak, süreyle değişimlerini gösteren grafikler (a) Cp-Ti, (b) Ti6Al4V

Tablo 1. Cp-Ti ve Ti6Al4V alaşımının 600,650 ve $700{ }^{\circ} \mathrm{C}$ sıcaklık aralığındaki oksidasyon hızı (k)

\begin{tabular}{cccc}
\multicolumn{4}{c}{ değerleri } \\
\hline Oksidasyon sıcaklığı & $\mathbf{6 0 0}^{\mathbf{}} \mathbf{C}$ & $\mathbf{6 5 0}^{\circ} \mathbf{C}$ & $\mathbf{7 0 0}^{\mathbf{}} \mathbf{C}$ \\
\hline Cp-Ti Oksidasyon hızı (k) $\mathrm{mg}^{2} \mathrm{~cm}^{-4} \mathrm{~h}^{-1}$ & 0.02185 & 0.1901 & 0.9861 \\
\hline Ti6Al4V Oksidasyon hızı $(\mathrm{k}) \mathrm{mg}^{2} \mathrm{~cm}^{-4} \mathrm{~h}^{-1}$ & 0.02432 & 0.10755 & 0.42115 \\
\hline
\end{tabular}

Şekil 5 (a) ve (b)'de Cp-Ti ve Ti6A14V numunelerinin çalışılan oksidasyon sıcaklıkları için çizilen $\operatorname{lnK}-1 / \mathrm{T}$ grafikleri verilmiştir. Grafiğgin eğiminden, her bir numune için oksidasyon aktivasyon enerjisi "Q" değerleri hesaplanmıştır. Cp-Ti için aktivasyon enerjisi 269.4kJ/mol iken Ti6Al4V için aktivasyon enerjisi $201.3 \mathrm{~kJ} / \mathrm{mol}$ hesaplanmıștır. Aktivasyon enerjisi değerinin yüksek olması, bu reaksiyonun sıcaklık değişimine çok duyarlı olduğunu gösterir. Yüksek aktivasyon enerjili reaksiyonlar, yüksek sıcaklık değişimlerinden daha fazla etkilenmektedirler. Yani oksidasyon hızı yükselir. 
Ti alaşımı ve saf Ti'un Q değerleri karşılaştırıldığında, Ti6Al4V alaşımı için oksidasyon aktivasyon enerjisinin daha düşük olduğu görülmektedir. Bunun sebebi olarak, alüminyumun oksijene olan afinitesine bağlanabilir. Yapılan literatür $[15,16]$ çalışmalarında da benzer sonuçlar çıktığı tespit edilmişstir.
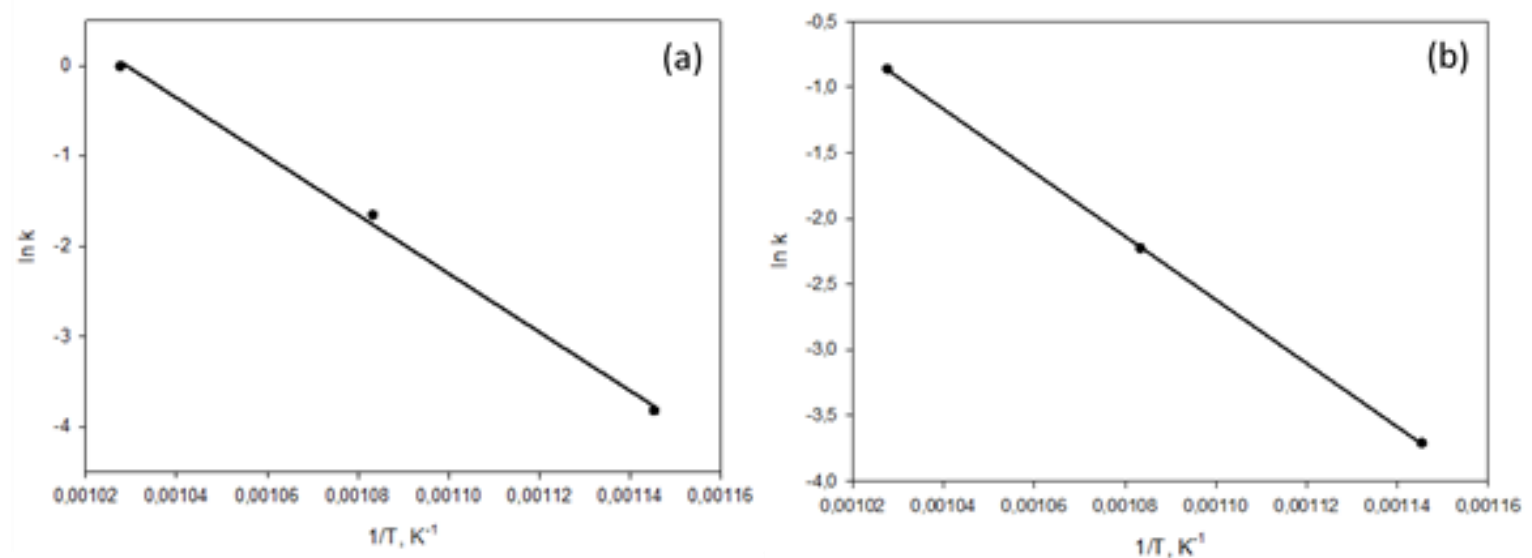

Şekil 5. (a) CP-Ti'a ve (b) Ti6Al4V'a ait lnD-(1/T) grafikleri

Cp-Ti ve Ti6Al4V alaşımının 48 saat $650{ }^{\circ} \mathrm{C}$ 'deki ve Ti6Al4V için 48 saatte, $700{ }^{\circ} \mathrm{C}$ 'deki XRD analizi sonuçları şekil 6'da verilmiştir. Titanyum oksit doğada farklı polimorflar da yani birden fazla kristal yapı da bulunmaktadır; bunlardan en çok tercih edilen ve kararlı olan $\mathrm{TiO}_{2}$ formu rutiledir, diğer formları ise anatase ve brookittir [17,18]. Alınan XRD sonuçlarında numune yüzeyin de rutile ve anatase oluşumu görülmüştür. İstenilen faz oluşumu her iki numunede de elde edilmiştir.

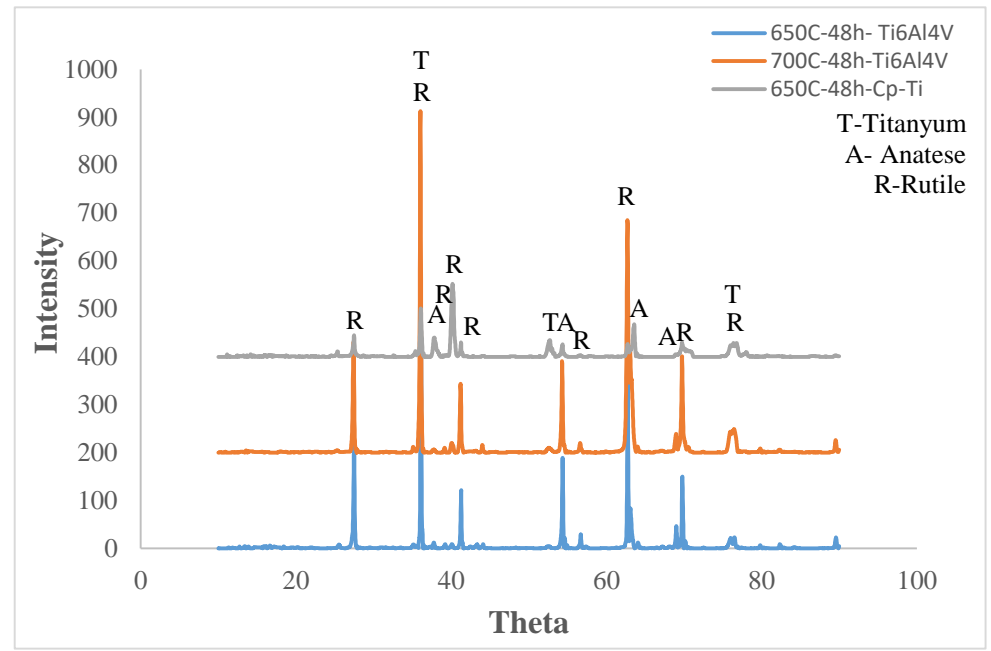

Şekil 6. Cp- Ti ve Ti6Al4V alaşımının 650 ve $700^{\circ} \mathrm{C}$ 'de 48 saat sonrası XRD analizleri

\section{Sonuçlar}

Cp- Ti ve Ti6Al4V alaşımının 600,650 ve $700{ }^{\circ} \mathrm{C}$ aralığındaki sıcaklıklarda termal oksidasyon kinetiğinin incelendiği bu deneysel çalışmada aşağıda özetlenen sonuçlar elde edilmiştir:

$\checkmark$ Termal oksidasyon işlemi sonrasında (değişen süre ve sıcaklık ile) tüm numune yüzeylerinde oksit tabakası oluşmuştur. Oluşan oksit tabakası $\left(\mathrm{TiO}_{2}\right)$ anatas ve rutil formundadir. 
600, 650, $700{ }^{\circ} \mathrm{C}$ 'de gerçekleştirilen izotermal oksidasyon deneylerinden, Ti6Al4V'un 600 ${ }^{\circ} \mathrm{C}$ hesaplanan $k$ değerlerinin $\mathrm{Cp}$-Ti'den daha yüksek olduğu, 650 ve $700{ }^{\circ} \mathrm{C}$ 'de ise çok daha düşük olduğu tespit edildi.

Cp-Ti için aktivasyon enerjisi $269.4 \mathrm{~kJ} / \mathrm{mol}$ iken Ti6Al4V için aktivasyon enerjisi $201.3 \mathrm{~kJ} / \mathrm{mol}$ hesaplanmıştır. $\mathrm{Bu}$ değerlerin kendi içeresinde literatürdeki oksidasyon işlemleri için gerekli aktivasyon enerjisi değerleriyle benzerlik gösterdiği görülmüştür.

\section{Teşekkürler}

Çalışma sırasında laboratuvar imkânlarından yararlandığımız Sakarya Üniversitesi, Mühendislik Fakültesi, Metalurji ve Malzeme Mühendisliği Bölümüne teşekkürü bir borç biliriz.

\section{Kaynaklar}

[1]. Aniołek K., Kupka M., Mechanical, tribological and adhesive properties of oxide layers obtained on the surface of the Ti-6Al-7Nb alloy in the thermal oxidation process, Wear, 2019, 432-433.

[2]. Ayday A., Coatings of Bioactive TiO2 Films on TI6AL4V Alloy by Micro Arc Oxidation, Acta Physica Polonica A, 2018, 134, 412-414.

[3]. Astinchap B., Moradian R., Gholami K., Effect of sputtering power on optical properties of prepared $\mathrm{TiO}_{2}$ thin films by thermal oxidation of sputtered Ti layers, Materials Science in Semiconductor Processing, 2017, 63, 169-175.

[4]. Sartale S.D., Ansari A.A., Rezvani S.-J., Influence of Ti film thickness and oxidation temperature on $\mathrm{TiO} 2$ thin film formation via thermal oxidation of sputtered Ti film, Materials Science in Semiconductor Processing, 2013, 16, 2005-2012.

[5]. Özkan O., Mindivan H., An Electrodeposition Method of Nickel-Graphene Composite Coatings on Ti-6Al-4V alloy, Bilge International Journal of Science and Technology Research, 2018, 2, 47-52.

[6]. Kurt H. İ., Optimization of Tensile Strength of Al Alloys with Mg and Ti, El-Cezerî Journal of Science and Engineering, 2017, 4, 1, 25-31.

[7]. Li L., Yu K., Zhang K., Liu Y., Study of Ti-6Al-4V alloy spectral emissivity characteristics during thermal oxidation process, International Journal of Heat and Mass Transfer, 2016, 101, 699-706.

[8]. Byun J. M., Choi H. R., Kim S. H., Suk M.-J, Kim Y. D., Formation of nanostructured rutile $\mathrm{TiO} 2$ synthesized on Ti powder via thermal oxidation, Applied Surface Science, 2017, 415, 43-48.

[9]. Yang W., Xu D., Guo Q., Chen T., Chen J., Influence of electrolyte composition on microstructure and properties of coatings formed on pure Ti substrate by micro arc oxidation, Surface and Coatings Technology, 2018, 349, 522-528.

[10]. Aniołek K., Kupka M., Dercz G., Cyclic oxidation of Ti-6Al-7Nb alloy, Vacuum, 2019, 168, 108859.

[11]. Krnel K., Sciti D., Landi E., Bellosi A., Surface modification and oxidation kinetics of hotpressed AlN-SiC-MoSi2 electroconductive ceramic composite, Applied Surface Science, 2003, 210, 274-285.

[12]. Rajabi A., Mashreghi A.R., Hasani S., Non-isothermal kinetic analysis of high temperature oxidation of Ti-6Al-4V alloy, Journal of Alloys and Compounds, 2020, 815, 151948. 
[13]. Liu Z., Wang W., Liu H., Wang T., Qi M., Formation and characterization of titania coatings with cortex-like slots formed on Ti by micro-arc oxidation treatment, Applied Surface Science, 2013, 266, 250-255.

[14]. Aniołek K., Barylski A., Kupka M., Modelling the structure and mechanical properties of oxide layers obtained on biomedical $\mathrm{Ti}-6 \mathrm{Al}-7 \mathrm{Nb}$ alloy in the thermal oxidation process, Vacuum, 2018, 154, 309-314.

[15]. Ostrovskaya O., Badini C., Baudana G., Padovano E., Biamino S., Thermogravimetric investigation on oxidation kinetics of complex Ti-Al alloys, Intermetallics, 2018, 93, 244250.

[16]. Aniołek K., Kupka M., Barylski A., Dercz G., Mechanical and tribological properties of oxide layers obtained on titanium in the thermal oxidation process, Applied Surface Science, 2015, 357, 1419-1426.

[17]. Rahimi N., Pax R. A., Gray E. M. A., Review of functional titanium oxides. I: TiO2and its modifications, Progress in Solid State Chemistry, 2016, 44, 86-105.

[18]. Fargas G., Roa J.J., Sefer B., Pederson R., Antti M.-L., Mateo A., Influence of cyclic thermal treatments on the oxidation behavior of Ti-6Al2Sn-4Zr-2Mo alloy, Materials Characterization, 2018, 145, 218-224. 